\title{
Multipurpose medical assistant robot (Docto-Bot) based on internet of things
}

\author{
Md. Anowar Hossain 1 , Md. Ebrahim Hossain², Mohammad Anisur Rahaman ${ }^{3}$ \\ ${ }^{1,3}$ Department of Electronics and Telecommunication Engineering, Chittagong University of Engineering and \\ Technology, Bangladesh \\ ${ }^{2}$ Department of Electrical and Electronics Engineering, Port City International University, Bangladesh
}

\begin{tabular}{l} 
Article Info \\
\hline Article history: \\
Received Dec 3, 2020 \\
Revised May 21, 2021 \\
Accepted Jun 11, 2021 \\
\hline
\end{tabular}

\section{Keywords:}

Docto-Bot

ECG

IoT

Medical assistant robot

Medicine reminder

Patient monitoring system

Pulse oximeter

\begin{abstract}
The world's population is growing every day, and so is the number of patients. People's life expectancy is increasing due to technology's welfare, but the problem is that the health sector has always faced a shortage of inadequate doctors. This research main objective was to design and implement a biomedical-based medical assistant robot named "Docto-Bot" to deal with this problem. This research concerns this medical assistant robot's design and development for the disabled and the patients in need. Such a robot's prime utilization is to minimize person-to-person contact and ensure the cleaning, sterilization, and support in hospitals and similar facilities such as quarantine. This prototype robot consists of a medicine reminding and medicine providing system, Automatic hand sanitizer and IoT based physiological monitoring system (body temperature, pulse rate, ECG, Oxygen saturation level). A direct one-to-one server-based communication method and user-end android app maintaining system designed. It also included the controlling part, which control automatically and manually by users. Docto-Bot will play a very significant factor in bio-medical robot applications. Though the achievements described in the paper look fruitful and advanced, shortcomings still exist.
\end{abstract}

This is an open access article under the $\underline{C C B Y-S A}$ license.

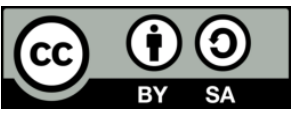

Corresponding Author:

Md. Anowar Hossain

Department of Electronics and Telecommunication Engineering

Chittagong University of Engineering and Technology

Department of ETE, CUET, Pahartoli, Raozan-4349, Chittagong, Bangladesh

Email: anowarhossain.cuet@gmail.com

\section{INTRODUCTION}

Nowadays, advanced mechanics are all over the place. Humans are encircled by innovation in each respect of life. Without innovation, men aren't capable of leading their life with full of joy. Simultaneously, our dependency on machines has evolved in the same way that technologists make our lives easier through discoveries. To improve the experience, we update our rationale, frameworks, philosophy and everything. Because of expanding the populations worldwide, Doctors and Medical assistants can't look after properly as they want.

According to the WHO member status report [1], we have less than one doctor per thousand people for providing proper support in medical health issues in our world. In case of an emergency like the present corona pandemic, this inadequacy is even more noticeable. As a result, Doctors, Nurses and Medical assistants are forced to serve everyone and become more vulnerable to their family and themselves, which is increasing the rate of contact with more affected people. Moreover, poverty has become a significant issue in 3rd world countries [2]. More people need more nurses for checkups and this increases the level of spending in the health sector. In this case, a robot could obtain some initial information (such as body temperature, 
BPM, oxygen saturation level, ECG) of the patient without the doctor or nurse's direct contact, and it could significantly reduce those problems. On the other hand, even in matters like round-check of the patient, giving medicine as per the prescription, talking directly to the doctor-even if the doctor does not go directly to the patient physically and this robot can largely overcome the doctor's inadequacy. And at the end of the day, this robot will significantly reduce the cost of routine checkups per capita in the health sector by hospitals. As a result, patients will also receive a low-cost healthcare service.

In recent years, many pieces of research have been developed in this sector individually. We went through various works on medical assistance [3] autonomous robots [4]. The majority of medical personal wanted to control their assistant robot over the internet [5]. Another paper named as FASTele-A TeleEchography portable robot system can be used by any paramedic for an emergency purpose [6]. There have been some methods on the PMS (patient monitoring system) [7], advanced healthcare [8], smart healthcare [9], digital thermometer [10], Non-contact Infrared Thermometer [11]. A pulse oximeter design based on Raspberry [12], pulse oximeter [13], heartbeat monitoring [14], IoT device for heart problem detection [15] and Temperature-Humidity measurement system [16] has already been acknowledged in our work. We thought of using a unique robotics utilization and prescribed medicine care [17] for the healthcare digitalization sector [18]. In the controlling portion, some research based on path-finding autonomous movement [19], obstacle avoidance [20], [21], some are based on android app related user-end manual controlling [22]. As we sort out this research and summarize this, we have concluded that a complete solution can only be achieved by combining these three points. Those are: i) Mobility-movement and transportation characteristic from one location to another, ii) Physiological monitoring-to evaluate the physiological conditions of patients and monitor their health status remotely, iii) Assistance with daily activities- help in carrying out activities related to self-care.

Thus, this paper aims to represent Docto-Bot, a biomedical-based humanoid autonomous robot, by maintaining those three parameters. In particular, we refer Docto-Bot to hospitals to reduce nurses and medical assistants' direct workload. A proof-of-concept and the prototype is presented in this work. Experimental results show insights that this Docto-Bot can be used as a medical assistant.

\section{RESEARCH METHOD}

This segment presents and portrays the proposed framework strategies that incorporate the framework system overview in section 2.1, system architecture in section 2.2, design and implementation in segment 2.3. This paper is the upgraded version of [23].

\subsection{System overview}

The three parameters are mentioned, which include Mobility and movement, Physiological monitoring, Assistance with daily activities. The whole system consists of an IP camera, sensors, microcontroller unit, Wi-Fi module, GSM module, RTC module, LCD, OLED display, automatic sanitizer unit, motor driver and motors; a block diagram of the proposed system present in Figure 1.

\subsection{System architecture}

We have divided the physiological monitoring system into two portions; Figures 2 and 3 represents that architecture. To remind medicine time and medicine name Docto-Bot has assistance with daily activities system. Figure 4 presents the medicine reminding and medicine providing system. For mobility and movement control, the architecture in Figure 5 is presented. In automatic mode, the IR sensor detects the path by line following robot (LFR) system and the Ultrasonic sensor detects the track's obstacle. And in the manual control system, an android app and Wi-Fi module work as a serial communication system.

\subsection{Design and implementation}

This segment offers and describes the techniques of the proposed model that include the device physiological monitoring system defines in section 2.3.1, assistance with daily activities in section 2.3.2 and control system in section 2.3.3.

\subsubsection{Physiological monitoring system}

In the physiological monitoring system, we were implied different sensors. We used (MLX-06914) sensor to measure body temperature, which senses the patient's body temperature by using infrared rays and transferring the data to Arduino (Mega 2560). After that, Arduino processes all this data and gradually shows it on the LCD and android app; this is present in Figure 6(a). When the suspect's temperature crosses $100^{\circ} \mathrm{F}$ level, the system will alarm and Docto-Bot will send an SMS to authorized people [24] via GSM module. If it's necessary, the suspect can check pulse rate via Docto-Bot. When the suspect's pulse is active, the BPM value will then appear in the display and an android application. If the BPM rate is upper than 130 or below 
60, the alarm will ON and Docto-Bot will send an SMS to authorized people. Then suspects can check the oxygen saturation level via Docto-Bot. If blood circulation is present, the $\mathrm{SpO}_{2}$ value will appear in LCD. While the $\mathrm{SpO}_{2}$ level is less than $90 \%$, the alarm will $\mathrm{ON}$.

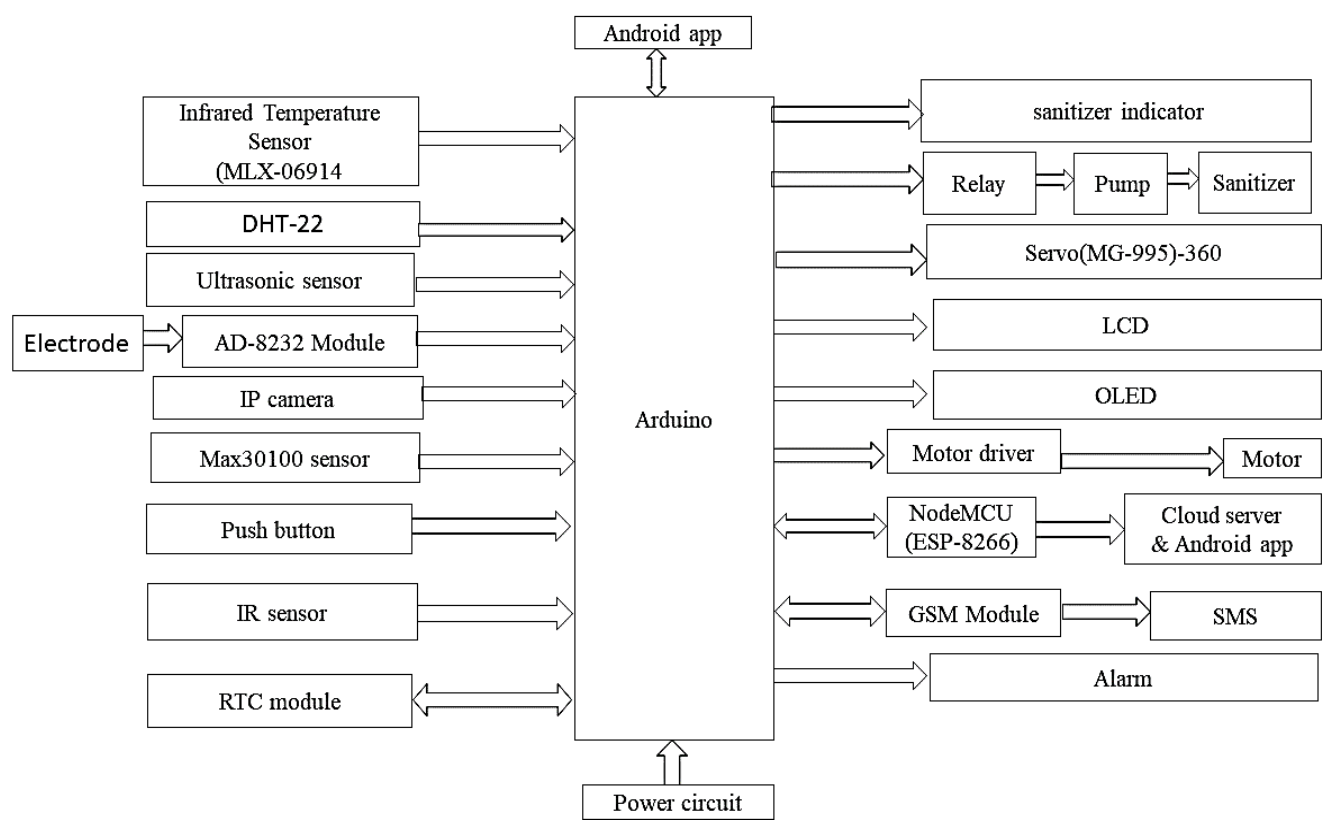

Figure 1. Block diagram of the proposed system including- mobility and movement, physiological monitoring, assistance with daily activities

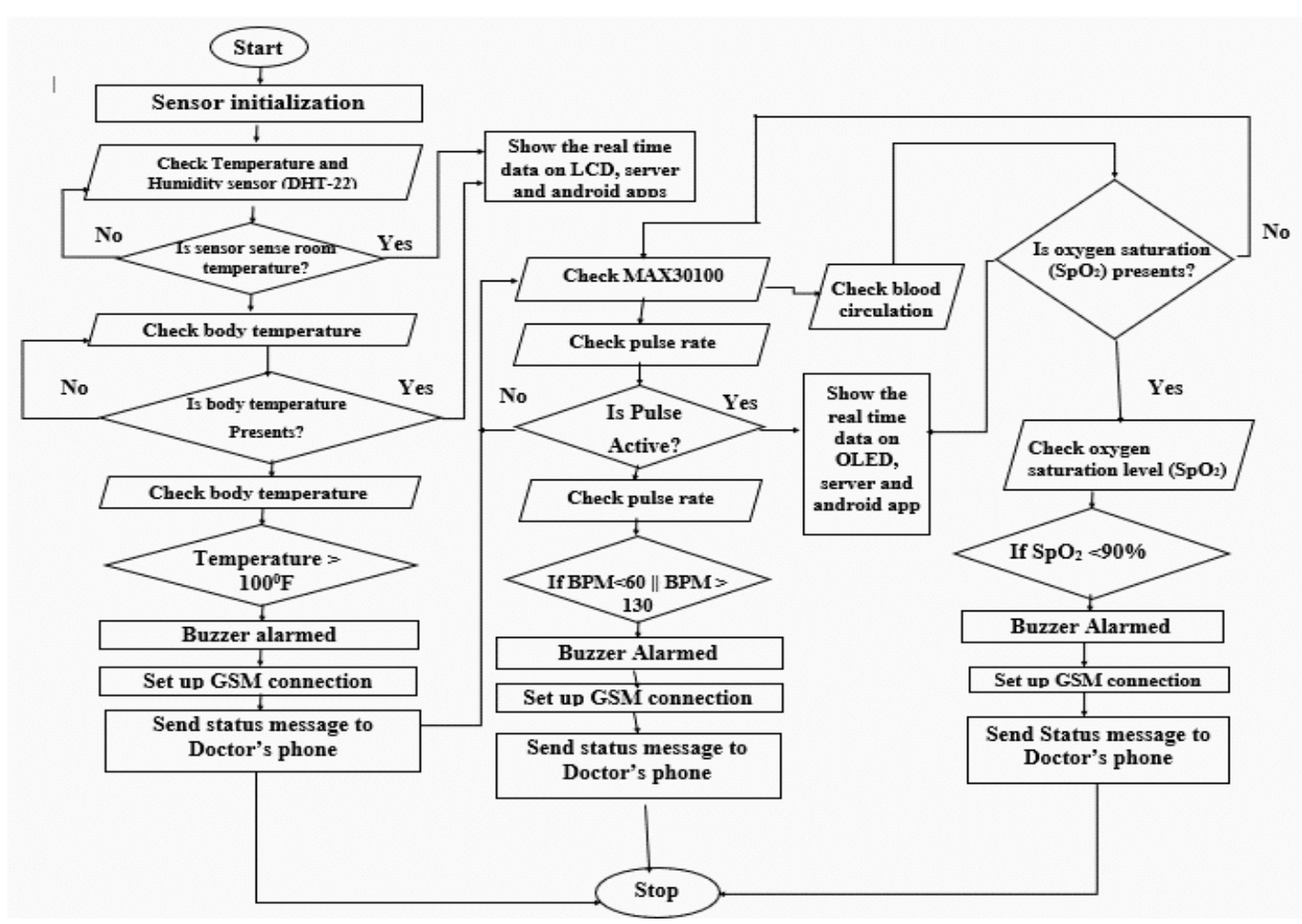

Figure 2. Flow chart of the physiological monitoring system (body temperature, pulse rate, oxygen saturation level, room temperature and humidity monitoring system) 


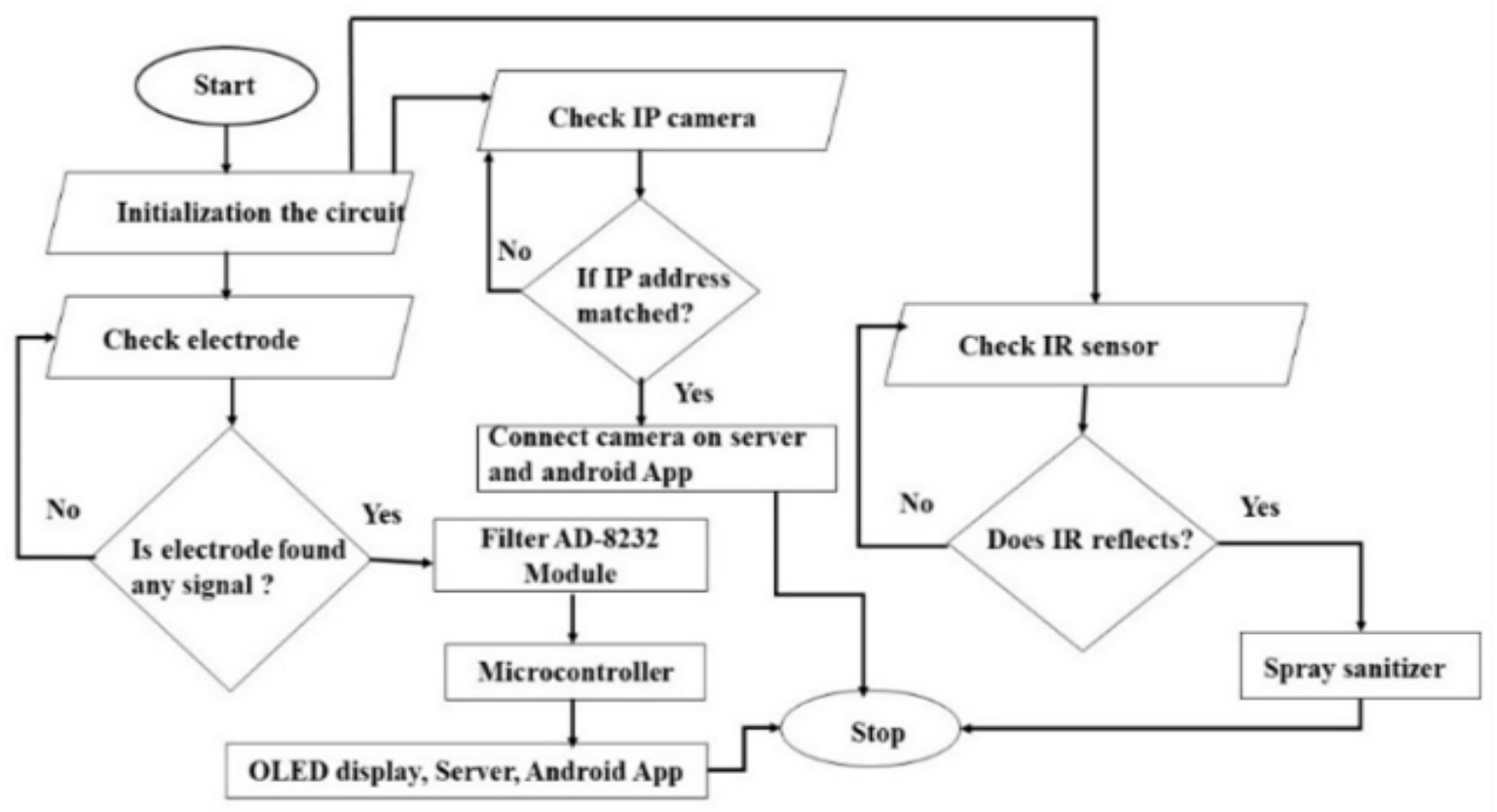

Figure 3. Flow chart of the physiological monitoring system (ECG, IP camera and automatic sanitizing system)

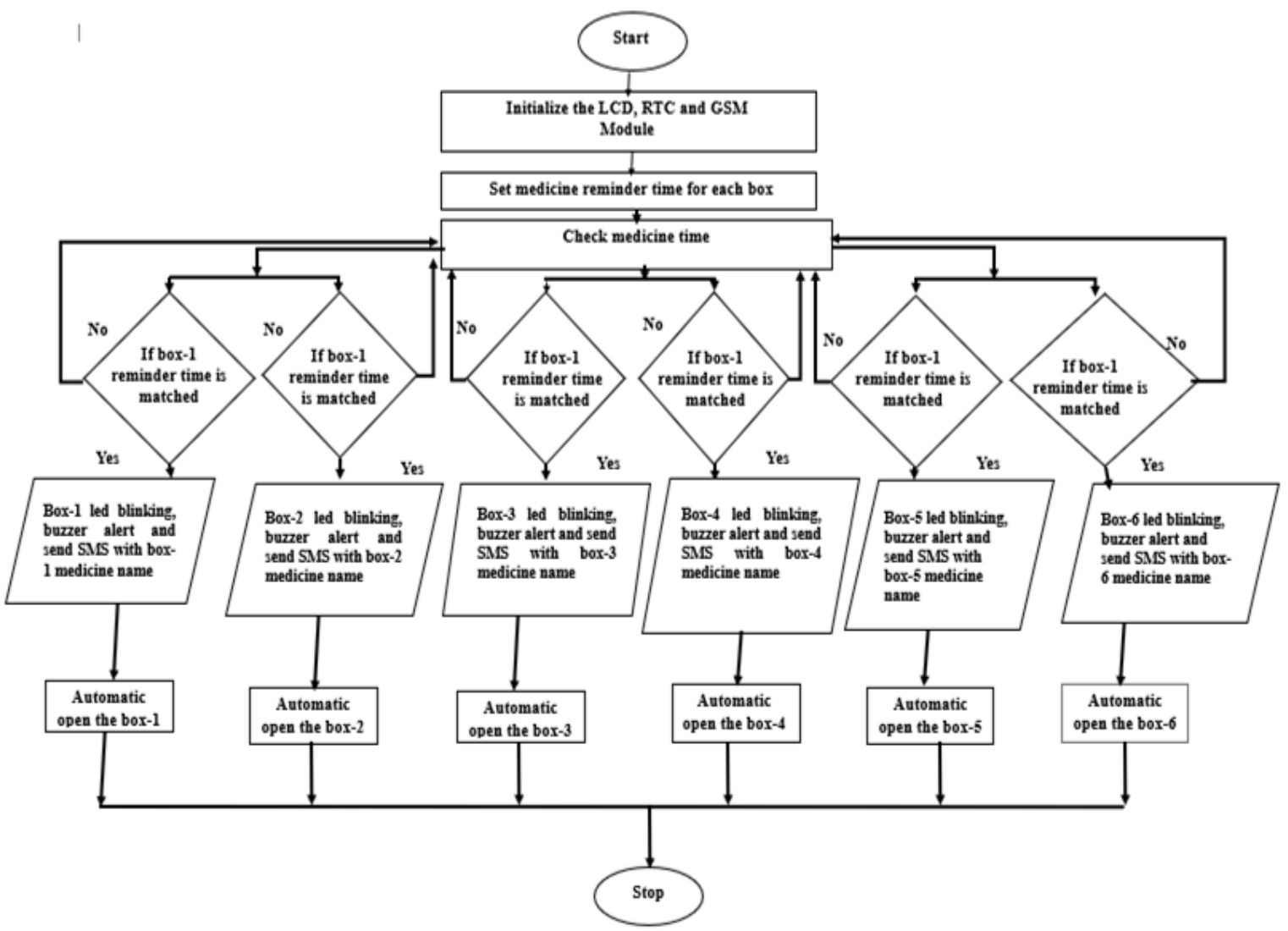

Figure 4. Flow chart of medicine reminding and medicine providing system for separate six medicine schedule 


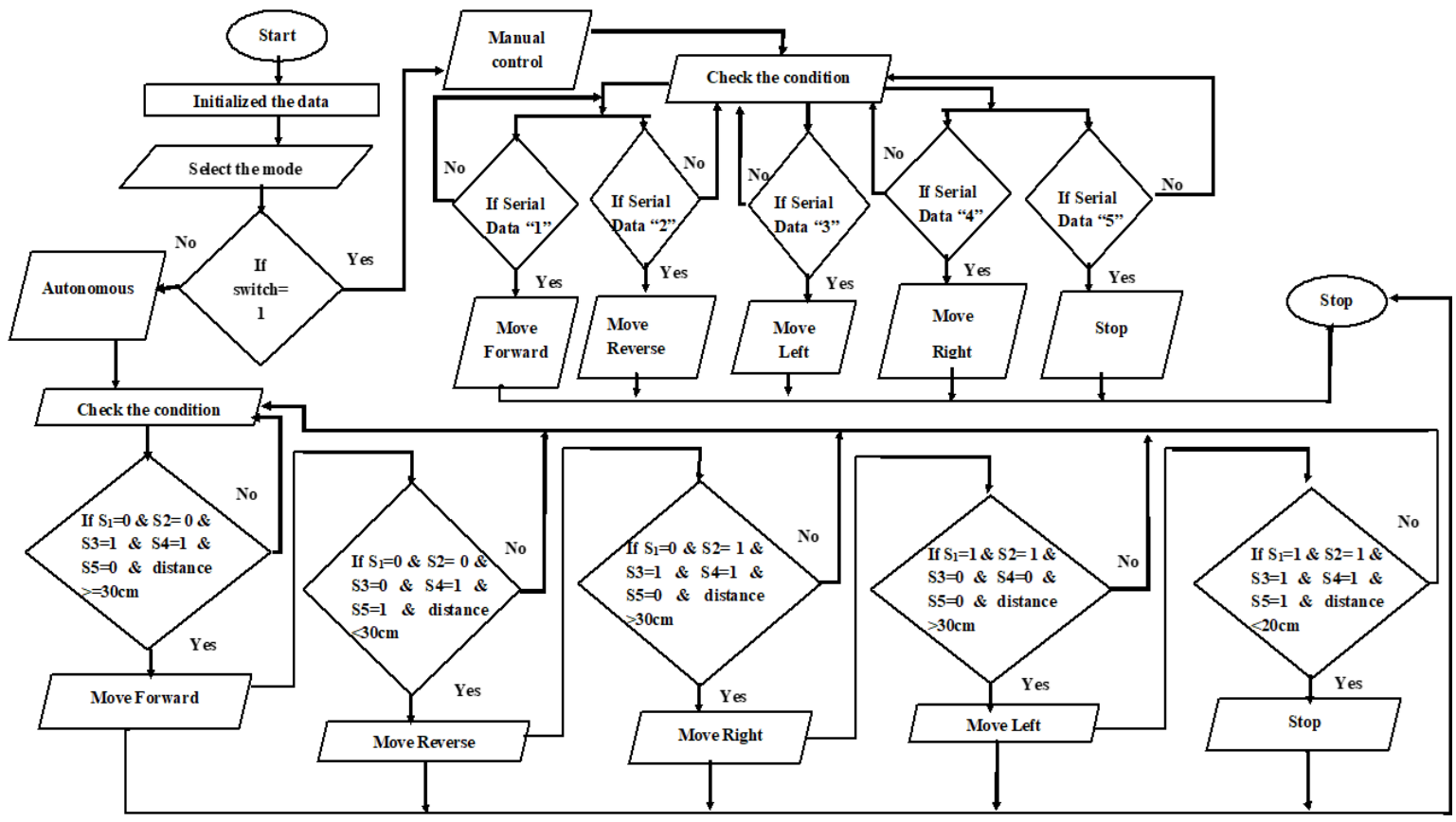

Figure 5. Flow chart of mobility and movement system architecture for both in automatic and manual mode

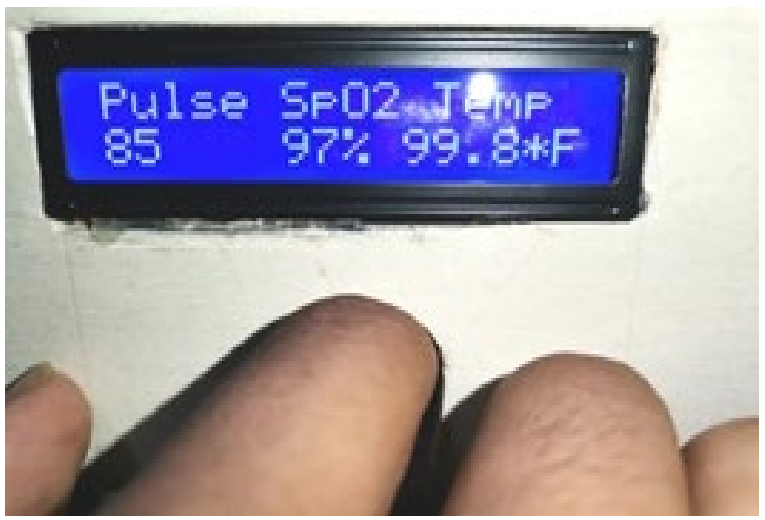

(a)

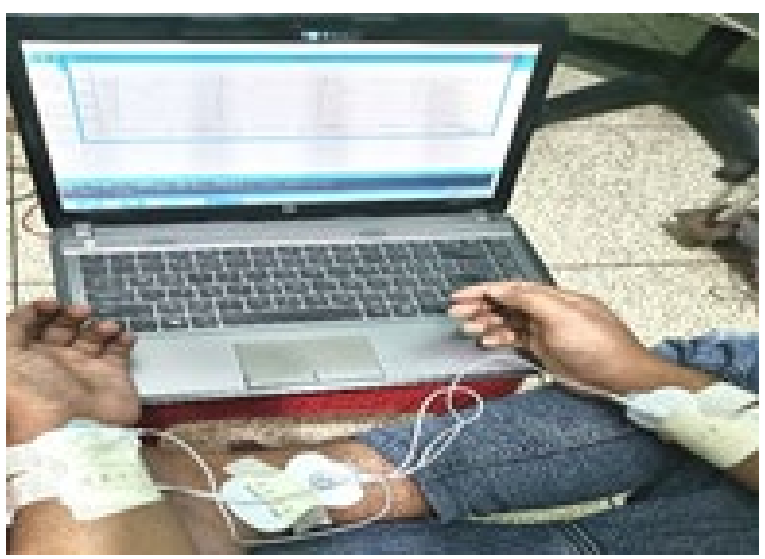

(b)

Figure 6. This figure are, (a) body temperature, pulse rate and oxygen saturation level shown in LCD,

(b) taking patients electro-cardio graph (ECG) by the three-electrode method 
Suspects can also measure ECG [25] by three-electrode method in Figure 6(b). For sensing the ECG signal, the electrodes are used and for filtering the ECG signal AD-8232 module. A Microcontroller is present for making a decision. Microcontroller collects the data from the AD-8232 module and processes it. The graphical representation of the data will appear in an Arduino serial monitor in Figure 7. The microcontroller will also transfer the data to the server via a Wi-Fi module. For communication between suspect and authorized person via video conference, we conduct an IP camera on Docto-Bot. IP camera will show live streaming video [26] on the android application and also on the cloud server.

\subsubsection{Assistance with daily activities}

To remind medicine time and medicine name, Docto-Bot has a medicine reminder system. This system also provides medicine. RTC module used to hold the remote time clock [27]. The system has six boxes; accordingly, based on the timing of taking the medication. By using pushbuttons, the medicine reminder time is set for each box. Then the system is checked the medicine reminder time for each package. If the time is matched, the system is alarmed, blink LED on the specific box and automatically opened using a servo motor [28] in Figure 8(a). Besides, an SMS is sent to the patient and caregiver to including the medicine name and medicine taken time. Here, all of the data is processed by Arduino. For measuring the room temperature and humidity DHT-22 sensor has been used. Microcontroller collects the sensor data and shows the data in LCD, cloud server [29], android app in Figure 8(b).

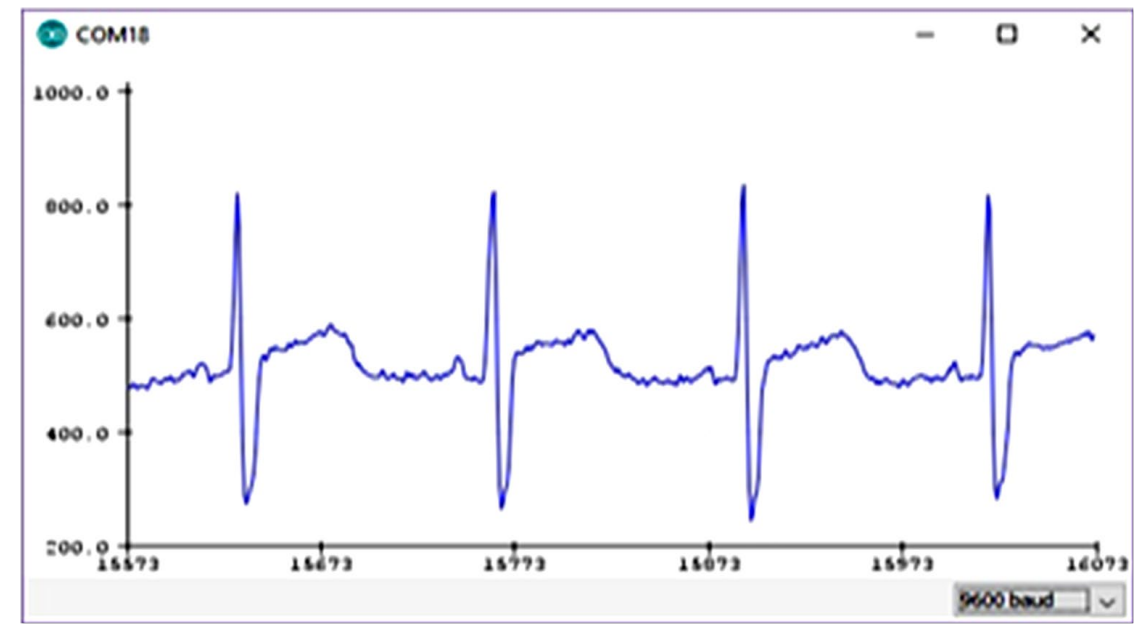

Figure 7. The graphical representation of ECG appeared in an Arduino serial monitor

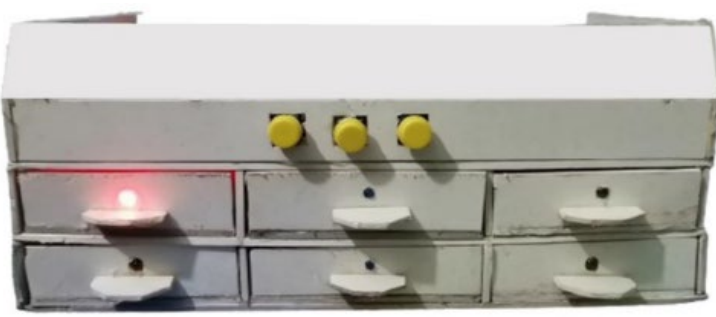

(a)

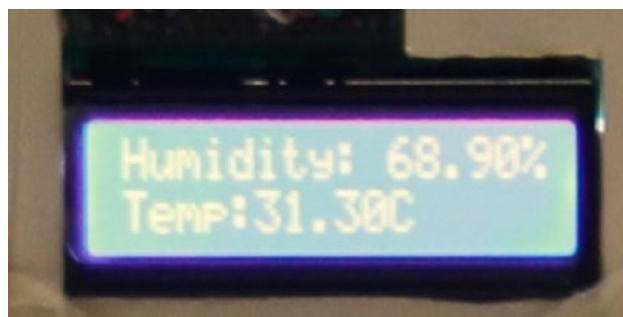

(b)

Figure 8 . This figure are, (a) medicine reminder and medicine providing system for assistance with daily activities, (b) the room temperature and humidity results displaying through LCD

\subsubsection{Control system}

Docto-Bot has two control systems. These are autonomous control mode and manual control mode. For autonomous mode, an ultrasonic sensor, a servo motor, four $12 \mathrm{~V}$ DC gear motor, and Five IR sensor is used. IR sensor detects the path by line following robot [30] system, and the Ultrasonic sensor detects the track's obstacle. To see the barrier towards the whole area, we use a servo motor to rotate the ultrasonic sensor at $360^{\circ}$ angles and the full system is working as required programming in the following Figures 9(a) and 9(b). 
In the manual control system, an android app and a Wi-Fi module are used. Android app works as a transmitter and the microcontroller \& Wi-Fi module works as a receiver. Using the serial communication method, we control Docto-Bot left, right, forward, reverse, and stop using the android app. Besides, all this processed data in physiological monitoring system along with the autonomous controlling system described here displayed in an android application in Figure 10. All the processed data sent to the cloud server mentioned here has been done through the IoT system in Figure 11.

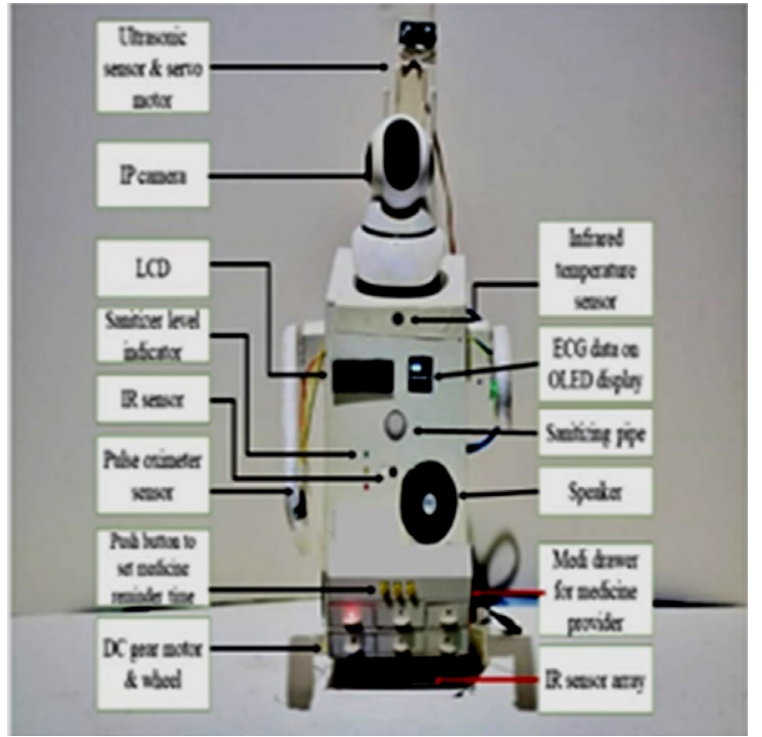

(a)

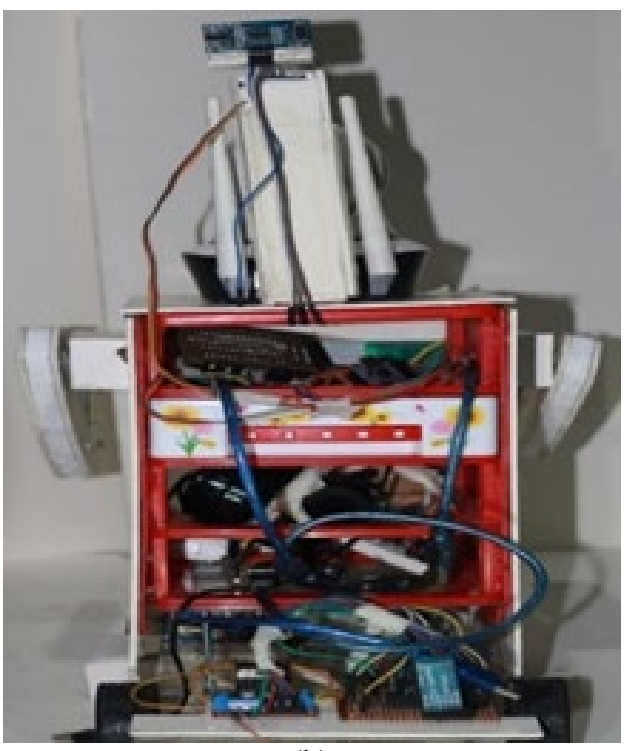

(b)

Figure 9. This figure are, (a) front view of Docto-Bot including a physiological monitoring system, automatic sanitizer, room temperature and humidity monitoring, two control system, IP camera, medicine reminder and provider system, (b) back view of Docto-Bot, including internal circuit
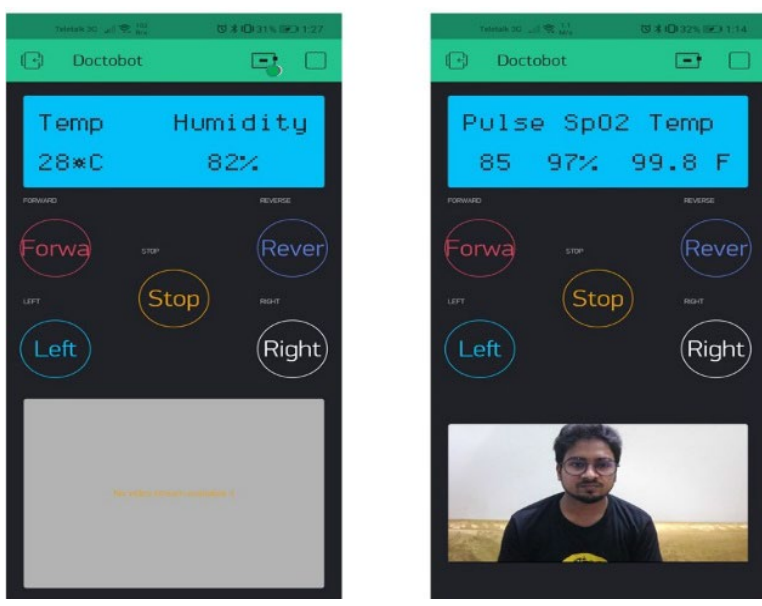

Figure 10. Displaying data for a physiological monitoring system and autonomous controlling system in the android software

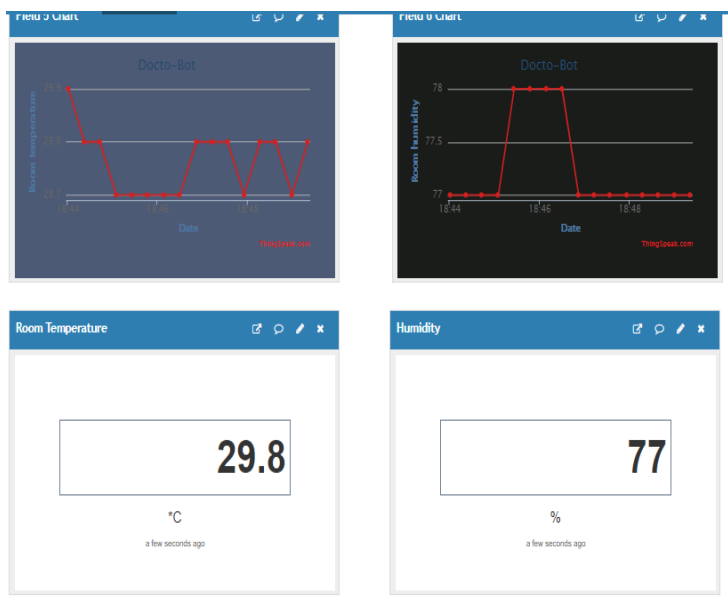

Figure 11. All the processed data sent to the cloud server through the IoT system

\section{RESULTS AND DISCUSSION}

We test the body temperature, pulse rate $(\mathrm{BPM})$ and oxygen saturation $\left(\mathrm{SpO}_{2}\right)$ level with twenty patients. The patient's data given in Table 1. Docto-Bot took patient temperature, pulse rate (BPM), and oxygen saturation level data are shown in the bar graph in Figure 12. At last, in this section, we present a comparison result between Docto-Bot and conventional medical equipment in Table 2 and Figure 13. 
Table 1. Docto-Bot measured twenty patient body temperature, pulse rate and oxygen saturation level data

\begin{tabular}{cccccc}
\hline Name of Patient & Age & Sex & BPM & Temperature $\left({ }^{0} \mathrm{~F}\right)$ & $\mathrm{SpO}_{2}(\%)$ \\
\hline A.T.M & 22 & Male & 88 & 98 & 100 \\
Jasim & 25 & Male & 73 & 96.8 & 98 \\
Rifat & 24 & Male & 95 & 99.8 & 98 \\
Sabbir & 25 & Male & 91 & 99.2 & 97 \\
Bappy & 37 & Male & 82 & 98.7 & 95 \\
Sayeed & 29 & Male & 90 & 96.2 & 99 \\
Shantanu & 35 & Male & 78 & 98.1 & 85 \\
Nasrin & 19 & Female & 89 & 89.6 & 89 \\
Tasnim & 42 & Female & 77 & 97.2 & 88 \\
Mahin & 24 & Female & 93 & 93.5 & 98 \\
Sorovi & 25 & Female & 95 & 93 & 96 \\
Rubi & 22 & Female & 92 & 95.7 & 99 \\
Juma & 25 & Female & 95 & 95 & 96 \\
Jamshed & 24 & Male & 82 & 98 & 96 \\
Lujaina & 25 & Female & 76 & 95.2 & 96 \\
Anowar & 25 & Male & 85 & 99.8 & 97 \\
Noha & 29 & Female & 76 & 98.1 & 89 \\
Sunny & 35 & Male & 73 & 98.8 & 79 \\
Arif & 19 & Male & 88 & 95.8 & 83 \\
Akhi & 19 & Female & 82 & 97.6 & 95 \\
\hline
\end{tabular}

\section{Docto-Bot taken Patient's Temperature, $\mathrm{SpO}_{2} \&$ BPM Data}

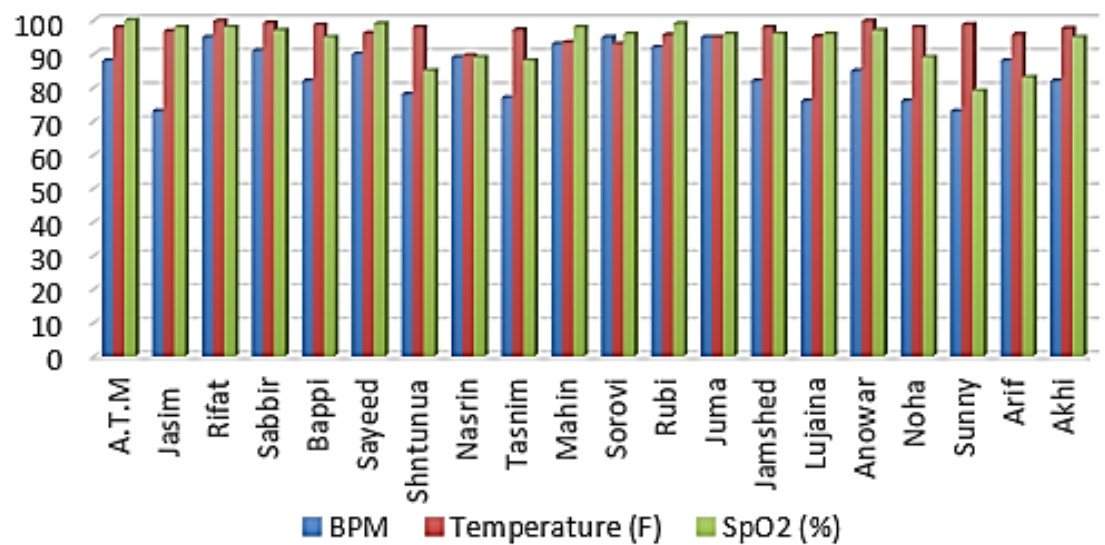

Figure 12. Docto-Bot takes testing data of body temperature $\left({ }^{0} \mathrm{~F}\right)$, pulse rate $(\mathrm{BPM})$, oxygen saturation $\left(\mathrm{SpO}_{2}\right)$ level for twenty patients

Table 2. A comparison results between Docto-Bot and conventional medical equipment

\begin{tabular}{|c|c|c|c|c|c|c|}
\hline $\begin{array}{c}\text { Name of } \\
\text { Patient }\end{array}$ & $\begin{array}{c}\text { BPM } \\
\text { (Docto-Bot) }\end{array}$ & $\begin{array}{c}\text { BPM } \\
\text { (Medical) }\end{array}$ & $\begin{array}{c}\text { Temperature }\left({ }^{0} \mathrm{~F}\right) \\
\text { (Docto-Bot) }\end{array}$ & Temperature $\left({ }^{0} \mathrm{~F}\right)$ (Medical) & $\mathrm{SpO}_{2}(\%)$ (Docto-Bot) & $\begin{array}{l}\mathrm{SpO}_{2}(\%) \\
\text { (Medical) }\end{array}$ \\
\hline A.T.M & 88 & 88 & 98 & 99 & 100 & 99 \\
\hline Jasim & 73 & 75 & 96.8 & 97 & 98 & 98 \\
\hline Rifat & 95 & 95 & 99.8 & 99.8 & 98 & 98 \\
\hline Sabbir & 91 & 91 & 99.2 & 98.8 & 97 & 97 \\
\hline Bappy & 82 & 83 & 98.7 & 98.7 & 95 & 95 \\
\hline Sayeed & 90 & 90 & 96.2 & 96.2 & 99 & 100 \\
\hline Shantanu & 78 & 79 & 98.1 & 98.1 & 85 & 85 \\
\hline Nasrin & 89 & 89 & 89.6 & 89.6 & 89 & 92 \\
\hline Tasnim & 77 & 77 & 97.2 & 97.2 & 88 & 95 \\
\hline Mahin & 93 & 93 & 93.5 & 93.5 & 98 & 97 \\
\hline Sorovi & 95 & 95 & 93 & 93 & 96 & 96 \\
\hline Rubi & 92 & 92 & 95.7 & 95.5 & 99 & 99 \\
\hline Juma & 95 & 90 & 95 & 95 & 96 & 96 \\
\hline Jamshed & 82 & 82 & 98 & 97 & 96 & 96 \\
\hline Lujaina & 76 & 77 & 95.2 & 95.2 & 96 & 93 \\
\hline Anowar & 85 & 89 & 99.8 & 99.8 & 97 & 98 \\
\hline Noha & 76 & 76 & 98.1 & 98.1 & 89 & 90 \\
\hline Sunny & 73 & 73 & 98.8 & 98.8 & 79 & 85 \\
\hline Arif & 88 & 88 & 95.8 & 94 & 83 & 92 \\
\hline Akhi & 82 & 84 & 97.6 & 98 & 95 & 95 \\
\hline
\end{tabular}




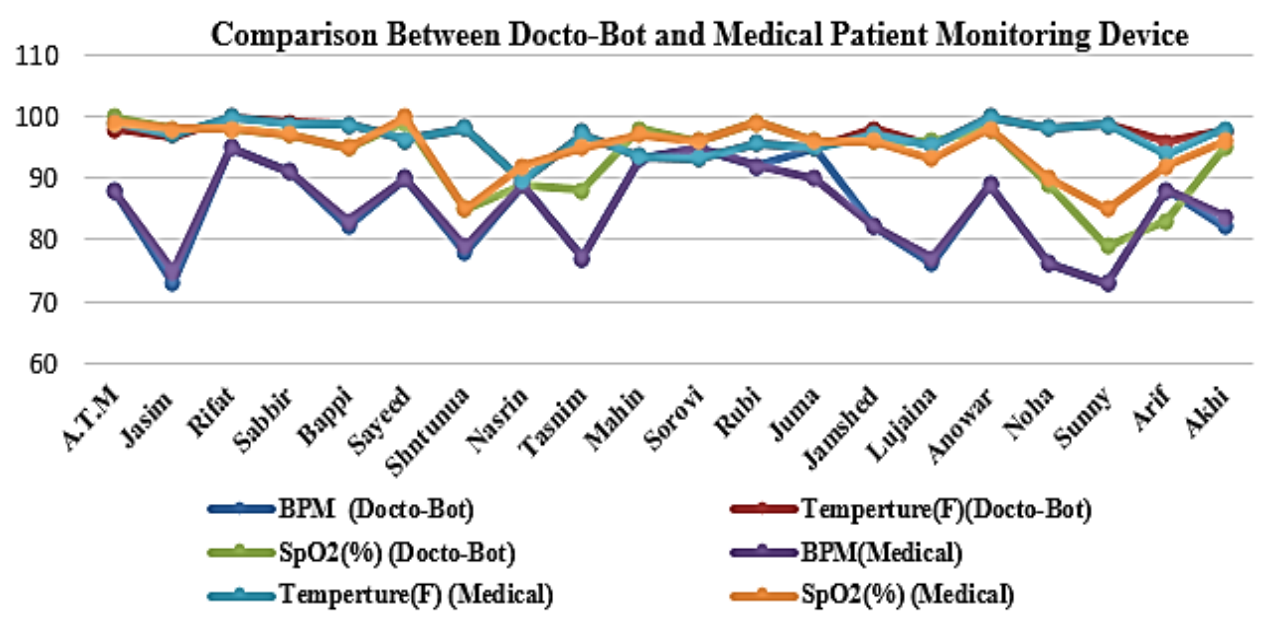

Figure 13. A graphical representation of the comparison result between docto-bot and conventional medical equipment

\section{CONCLUSION}

In this paper, we have worked on designing and developing the medical assistant robot "Docto-Bot" as primary patient monitoring and patient caring assistance with daily activities. For user friendly purpose we design "Docto-Bot" with manual and autonomous control system. Doctors from anywhere in the world will be able to show all patient data without touching the patient through the IoT system and make communicate video calls with the patient. We believe this robot will go a long way in alleviating the lack of adequate doctors in medical services around the world. Anyone who knows primary operating can also use Docto-Bot as a medical assistant in his family. Machine learning and AI system will be carried through in the future.

\section{REFERENCES}

[1] C. James et al., "A universal truth: No health without a workforce," 2013 World Health Organization, 2013.

[2] K. Connolly, "Poverty and human development in the Third World," Archives of Disease in Childhood, vol. 60, pp. 880-886, 1985.

[3] M. Sachit and C. M. Vidhyapathi, "Design of a medical assistant robot," 2017 2nd IEEE International Conference on Recent Trends in Electronics, Information and Communication Technology (RTEICT), 2018, pp. 877-881, doi: 10.1109/RTEICT.2017.8256723.

[4] R. Murai et al., "A novel visible light communication system for enhanced control of autonomous delivery robots in a hospital," 2012 IEEE/SICE International Symposium on System Integration (SII), 2012, pp. 510-516, doi: $10.1109 /$ SII.2012.6427311.

[5] C.-L. Hung, "The research of factors influencing advanced medical robot use," Quality and Quantity, vol. 55, no. 2, 2020, doi: 10.1007/s11135-020-01007-4.

[6] K. Ito, S. Sugano and H. Iwata, "Portable and Attachable Tele-Echography Robot system: FASTele," 2010 Annual International Conference of the IEEE Engineering in Medicine and Biology, 2010, pp. 487-490, doi: 10.1109/IEMBS.2010.5627123.

[7] M. Ali, A. A. Ali, A.-E. Taha, I. B. Dhaou and T. N. Gia," Intelligent Autonomous Elderly Patient Home Monitoring System” ICC 2019 - 2019 IEEE International Conference on Communications (ICC), 2019, pp. 1-6, doi: 10.1109/ICC.2019.8761204.

[8] N. S. Godbole and J. Lamb, "Research into Making Healthcare Green with Cloud, Green IT, and Data Science to Reduce Healthcare Costs and Combat Climate Change," 2018 9th IEEE Annual Ubiquitous Computing, Electronics \& Mobile Communication Conference (UEMCON), pp. 189-195, 2018, doi: 10.1109/UEMCON.2018.8796529.

[9] K. Mugoye, H. Okoyo and S. Mcoyowo, "Smart-bot Technology: Conversational Agents Role in Material Healthcare Support" 2019 IST-Africa Week Conference (IST-Africa), 2019, pp. 1-7, doi: 10.23919/ISTAFRICA.2019.8764817.

[10] M. Khizir, A. Md Shamsul and G. Rakesh, "Design of digital thermometer based on PIC16F77A single chip microcontrolle," 2013 3rd International Conference on Consumer Electronics, Communications and Networks, 2013, pp. 246-249, doi: 10.1109/CECNet.2013.6703317.

[11] Z. Zhang, H. Zhang and T. Liu, "Study on body temperature detection of pig based infrared technology: A review," Artificial Intelligence in Agriculture, vol. 1, pp. 14-26, 2019, doi: 10.1016/j.aiia.2019.02.002.

[12] S. Bakhri, E. Rosiana and R. C. Saputra, "Design of low-cost pulse oximetry based on Raspberry Pi," Journal of Journal of Physics: Conference Series, vol. 1501, 2020, Art. no. 1501012003, doi: 10.1088/1742$6596 / 1501 / 1 / 012003$. 
[13] C. A. A. Castellanos, R. M. G. Majano and U. S. M. Sanchez, "Low cost Pulse Oximeter using Arduino," 2019 IEEE CHILEAN Conference on Electrical, Electronics Engineering, Information and Communication Technologies (CHILECON), 2019, pp. 1-6, doi: 10.1109/CHILECON47746.2019.8988029.

[14] B. Sayan, P. Souptik, S. Rohan and B. Abhishek, "Heartbeat Monitoring Using IoT," 2018 IEEE 9th Annual Information Technology, Electronics and Mobile Communication Conference (IEMCON), 2018, pp. 894-900, doi: 10.1109/IEMCON.2018.8614921.

[15] C. Luis, R. Dahyana, T. Washington, A. Luis, O. Jaime and S. David, "Mobile IoT device for BPM monitoring people with heart problems," 2020 International Conference on Electrical, Communication, and Computer Engineering (ICECCE), 2020, pp. 12-13, doi: 10.1109/ICECCE49384.2020.9179293.

[16] M. Verma, V. Kumar and Sandeep, "Implementation of an IoT based Real Time Signal Acquisition System over the Cloud using ThingSpeak Platform for Multi-Zonal Temperature and Humidity Measurement," IJRTER, vol. 6, no. 7, 2020, doi: 10.23883/IJRTER.2020.6046.TPDXM.

[17] A. H. Huang, B. H. Kaffenberger, A. Reich, J. C. Szepietowski, S. Stander and S. G. Kwatra, "Pruritus Associated with Commonly Prescribed Medications in a Tertiary Care Center," Medicines, vol. 6, no. 3, 2019, Art. no. 84, doi: $10.3390 /$ medicines6030084.

[18] L. L. Velez, "The future of healthcare: The impact of digitalization on healthcare services performance," The Internet and Health in Brazil: Challenges and Trends, 2018, pp. 435-449, doi: 10.1007/978-3-319-99289-1 22.

[19] L. A. Trinh, M. Ekström and B. Cürüklü, "Multi-Path Planning for Autonomous Navigation of Multiple Robots in a Shared Workspace with Humans," 2020 6th International Conference on Control, Automation and Robotics (ICCAR), 2020, pp. 113-118, doi: 10.1109/ICCAR49639.2020.9108082.

[20] H. Vivek, R. Sahadev and M. Santanu, "Low Cost Obstacle Avoidance Robot," International Journal of Soft Computing and Engineering (IJSCE), vol. 3, no. 4, pp. 52-55, 2013, doi: 10.6084/M9.FIGSHARE.1327873.

[21] A. Md Sayedul, M. Md Anam, J. Haowen, A. Ahmed and Y. Kumar, "A sensor fusion methodology for obstacle avoidance robot," 2016 IEEE International Conference on Electro Information Technology (EIT), 2016, pp. 458-463, doi: 10.1109/EIT.2016.7535284.

[22] R. K. Jain, B. J. Saikia, N. P. Rai and P. P. Ray, "Development of Web-based Application for Mobile Robot using IOT Platform," 2020 11th International Conference on Computing, Communication and Networking Technologies (ICCCNT), 2020, pp. 1-6, doi: 10.1109/ICCCNT49239.2020.9225467.

[23] M. A. Hossain et al., "Design and Implementation of an IoT Based Medical Assistant Robot (Aido-Bot)," 2020 IEEE International Women in Engineering (WIE) Conference on Electrical and Computer Engineering (WIECONECE), Bhubaneswar, India, 2020, pp. 17-20, doi: 10.1109/WIECON-ECE52138.2020.9397958.

[24] J. A. Amusan and A. Augustine, "Ultrasonic Intruder Detection System with Short Message Service (SMS) Feedback," Open Science Journal of Electrical and Electronic Engineering, vol. 5, no. 3, pp. 24-29, 2018

[25] M. Jai, "A Smart Wear based Portable Health Monitoring System," 2020 IEEE International Students' Conference on Electrical, Electronics and Computer Science (SCEECS), 2020, pp. 1-6, doi: 10.1109/SCEECS48394.2020.68.

[26] S. K.-liang and W. T.-yuan, "A Novel Remote Access Control For The Real -Time Streaming Data of IP Cameras," International Journal of Database Management Systems (IJDMS), vol. 12, pp. 1-16, 2020.

[27] R. Ginne, P. S. Ranjan, P. Negi, G. Kavi and K. Saurabh, "The Real-Time Hardware of Smart Digital Alarm Clock Integrated with Microcontroller," Intelligent Communication, Control and Devices, vol. 624, pp. 1641-1649, 2019, doi: 10.1007/978-981-10-5903-2_170.

[28] M. Shanthini, G. Vidya and R. Arun, "IoT enhanced smart door locking system," 2020 Third International Conference on Smart Systems and Inventive Technology (ICSSIT), 2020, pp. 92-96, doi: 10.1109/ICSSIT48917.2020.9214288.

[29] R. Ab Rahman, H. U. Rabaah and A. Sabrina," IoT based temperature and humidity monitoring framework," Bulletin of Electrical Engineering and Informatics (BEEI), vol. 9, no. 1, pp. 229-237, 2020, doi: 10.11591/eei.v9i1.1557.

[30] J. Chaudhari, A. Desai and S. Gavarskar, "Line Following Robot Using Arduino for Hospitals," 2019 2nd International Conference on Intelligent Communication and Computational Techniques (ICCT), 2020, pp. 330-332, doi: 10.1109/ICCT46177.2019.8969022. 